\title{
Study on Bearing Capacity of Pile Foundation Based on High Strain Measured Curve Fitting Method
}

\author{
Guosheng Zhong ${ }^{*}$ and Zihang Huang \\ School of Architecture and Civil Engineering, Huizhou University, Huizhou, Guangdong 516007, China \\ ${ }^{*}$ Corresponding author
}

\begin{abstract}
In order to test the correctness and feasibility of high strain measured curve fitting method of pile, field tests of vertical bearing capacity of pile were carried out using prestressed concrete pipe pile. The following test results can be obtained: (1) According to the actual soil layer parameters of test sites, the relevant fitting parameters in dynamic model of pile and soil were modified; The fitting calculation programs were compiled by MATLAB, and the measured data of high strain were calculated; The calculated curves can fit well with the measured curves. (2) Compared with the static loading test results, the ultimate bearing capacity of pile of dynamic testing at two test sites was reduced by $13.03 \%$ and $11.35 \%$ respectively; The bearing capacity of pile measured by the high strain measured curve fitting method was relatively accurate. The research results can provide a theoretical basis for the design and bearing capacity testing of pile foundation.
\end{abstract}

Keywords-pile bearing capacity; static loading; heaped loading method; measured curve fitting

\section{INTRODUCTION}

Pile foundation is the most basic and the most safe and reliable foundation form in modern construction engineering [1]. In recent years, with the sustained and rapid development of China's economy, along with a variety of large buildings and high-rise buildings springing up, pile foundation is widely used because of its unique function, especially in seismic area, collapsible loess area, soft soil area, expansive soil area and frozen soil region. It has proved that pile foundation is a very effective, safe and reliable foundation [2-4].

Because China has vast territory, the engineering geological conditions in different regions are very different. The construction and detection of pile foundation under different geological conditions are often more complicated than the superstructure of the building, and the quality of foundation engineering has a direct impact on the safety of architectural engineering [5]. Compared with the static loading test, high strain dynamic test has many advantages, such as portable equipment, short test time, high sampling rate, low cost and high efficiency, and it has been widely recognized and adopted by the construction engineering field [6-8].

The existing pile-soil mechanics model does not fully consider the interaction mechanism between pile and soil in different regions, and can not accurately reflect the complexity of the pile-soil system in the actual region. Therefore, inevitably there are many assumptions and empirical components. According to engineering practice at home and abroad [7,8], compared with the static load test, high strain dynamic test of pile foundation has large errors. Therefore, according to the engineering geological conditions in a certain area, the pile-soil dynamics model and the value of relevant parameters are studied deeply. It is not only related to the quality and efficiency of engineering construction, but also a very important research topic in foundation engineering to determine reasonably and accurately the bearing capacity of pile foundation, which has important theoretical significance and engineering application value.

\section{ENGINEERING TEST SITE}

In order to accurately compare the bearing capacity of pile foundation under static load and high strain dynamic test, two test points were selected in a construction site of Huizhou Bailuhu scenic resort area. In the test, two test piles of the same specification were used, and parallel construction method was adopted at the same time. The distribution of soil layer of pile side in two test sites are shown in Table I and II.

TABLE I. DISTRIBUTIONS OF SOIL LAYER IN TEST SITE I

\begin{tabular}{ccc}
\hline $\begin{array}{c}\text { Number of } \\
\text { soil layer }\end{array}$ & Name of soil layer & $\begin{array}{c}\text { Thickness of } \\
\text { soil layer } / \mathrm{m}\end{array}$ \\
\hline 1 & Plain fill $\left(\mathrm{Q}^{\mathrm{ml}}\right)$ & 1.20 \\
2 & Fully weathered siltstone $(\mathrm{J})$ & 8.30 \\
3 & Strongly weathered siltstone $(\mathrm{J})$ & 5.90 \\
\hline
\end{tabular}

TABLE II. DISTRIBUTIONS OF SOIL LAYER IN TEST SITE II

\begin{tabular}{ccc}
\hline $\begin{array}{c}\text { Number of } \\
\text { soil layer }\end{array}$ & Name of soil layer & $\begin{array}{c}\text { Thickness of } \\
\text { soil layer } / \mathrm{m}\end{array}$ \\
\hline 1 & Plain fill $\left(\mathrm{Q}^{\mathrm{ml}}\right)$ & 1.50 \\
2 & Fully weathered siltstone $(J)$ & 6.30 \\
3 & Strongly weathered siltstone $(\mathrm{J})$ & 7.20 \\
\hline
\end{tabular}

III. PRINCIPLE AND EQUIPMENT OF STATIC AND DYNAMIC TEST

\section{A. Principle of Static Loading Test-Heaped Loading Method}

Single pile vertical compressive static loading test is a test method which is close to the actual working conditions of the vertical compression pile, and it is used to determine the 
vertical compressive bearing capacity of single pile. This test is currently recognized as the most intuitive and reliable test method to measure the vertical compressive bearing capacity of pile. It is usually regarded as a standard test method, which can be used as the basis for other test methods [9]. The object of static and dynamic contrast test is small and middle-sized pile, and the heaped loading method is generally used in the domestic testing institutions. The heaped loading method consists of heavy objects, secondary beams (universal beam), main beams, a jack, and so on, as shown in Figure I.

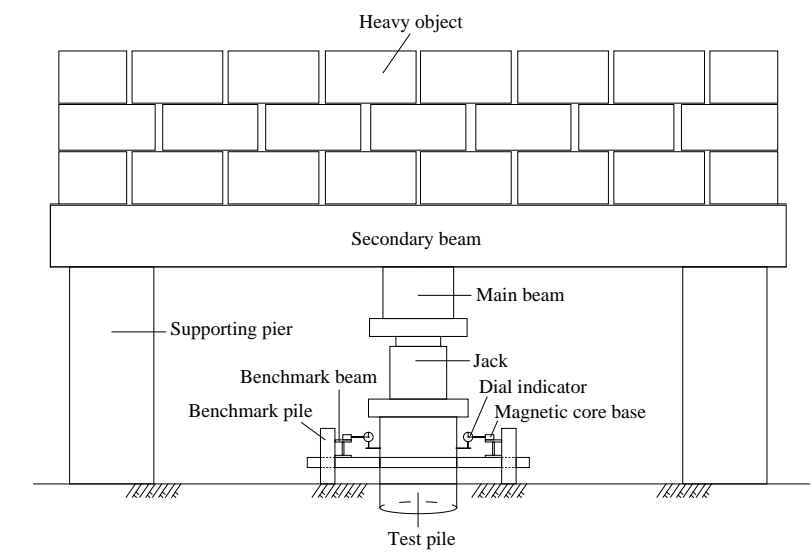

FIGURE I. SKETCH OF STATIC LOADING TEST OF PILE HEAPED LOADING METHOD

\section{B. Static Loading Test Equipment}

The static loading test system consists of a pressure platform reaction device, a loading device, a load measuring device, a displacement measuring device and an automatic collecting device. The reaction device is composed of heavy objects, secondary beams, main beams and a jack. The loading device is composed of a jack and an oil pump, and the load is applied by the jack. The maximum loading of the hydraulic jack is $2000 \mathrm{kN}$ in the test. The loading precision of the hydraulic pump station is $0.4 \mathrm{MPa}$, and the maximum loading value is 63MPa. The load measuring device is an oil pressure gauge, and the range of the oil pressure gauge is 60MPa. The displacement measuring device is composed of reference piles, reference beams and displacement sensors, and the range of the displacement sensor is $50 \mathrm{~mm}$. The automatic sampling device is a static loading tester, which collects the displacement readings under each loading.

\section{Principle of High Strain Dynamic test-Measured Curve Fitting Method}

The measured curve fitting method is based on the assumed pile-soil dynamic model, and the corresponding calculation program is compiled. Then the measured waveform curve is introduced into the calculating program, and the measured velocity wave curve (or measured force wave curve) is used as boundary condition. The value of force (or velocity) is calculated by adjusting the soil elastic limit, the maximum static resistance of soil and the damping coefficient of soil. Then the calculated curves are compared with the measured curves. If the results are not consistent, then continue to adjust the parameters of soil layers, until the calculated value are consistent with the measured value. At the same time, the parameters of soil are taken as the parameters of the actual soil. The maximum static resistance value of each layer is added and the total soil resistance is obtained. The ultimate bearing capacity of pile is calculated by this principle $[10,11]$. The specific analysis process is as follows:

The pile is considered as a continuous member model, which is divided into $\mathrm{N}$ elastic member units (the length of the unit is about $1 \mathrm{~m}$ ). The value of each unit length must be equal to the time of the stress wave passing through the unit, and the stress wave does not distort in the propagation process. The elastic modulus of each unit and the value of sectional area are derived from the elastic modulus and the sectional area of pile. At the same time, it is assumed that the soil resistance is at the bottom of each unit, and the variation of unit wave impedance only occurs at the junction of each unit. The lateral resistance of $\mathrm{N}$ units is R1, R2, ..., RN, and the end resistance is $\mathrm{Rb}$, as shown in Figure II.

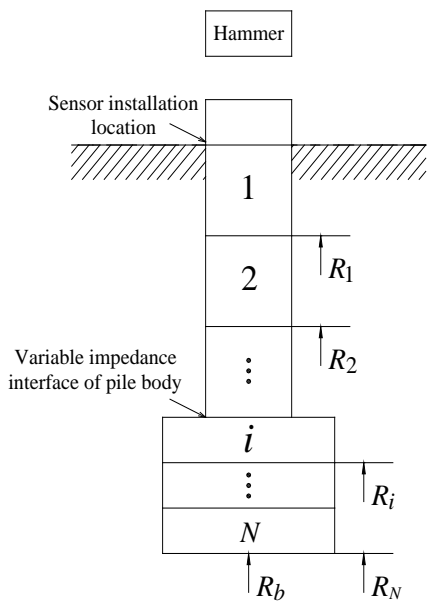

FIGURE II. DYNAMIC MODEL OF PILE AND SOIL

For the $j$ moment at the $i$ section of pile body, the traveling wave expression can be expressed as:

$$
\left\{\begin{array}{l}
P_{u}(i, j)=\frac{Z_{i+1}-Z_{i}}{Z_{i+1}+Z_{i}} P_{d}(i-1, j-1)+ \\
\frac{2 Z_{i}}{Z_{i+1}+Z_{i}} P_{u}(i+1, j-1)+\frac{Z_{i}}{Z_{i+1}+Z_{i}} R(i, j) \\
P_{d}(i, j)=\frac{2 Z_{i+1}}{Z_{i+1}+Z_{i}} P_{d}(i-1, j-1)+ \\
\frac{Z_{i}-Z_{i+1}}{Z_{i+1}+Z_{i}} P_{u}(i+1, j-1)-\frac{Z_{i+1}}{Z_{i+1}+Z_{i}} R(i, j)
\end{array}\right.
$$

Where $i=1,2, \ldots, N ; P_{u}(i, j)$ and $P_{d}(i, j)$ are respectively expressed as the up going wave force and the down going wave force of the $j$ moment at the $i$ section of pile body, and the unit is $\mathrm{N} ; Z_{i}=A_{i} \rho_{i} C_{i}$ is the wave impedance of the $i$ unit of pile body, and $A_{i}, \rho_{i}, C_{i}$ respectively for sectional area, density, velocity of longitudinal wave propagating in pile of the $i$ unit of pile body, and their units are respectively $\mathrm{m}^{2}, \mathrm{~kg} \cdot \mathrm{m}^{-3}, \mathrm{~m} \cdot \mathrm{s}^{-1}$. 


\section{High Strain Dynamic Test Equipment}

High strain dynamic test system is composed of sensors, pile foundation dynamic measuring instrument and excitation equipment. The main equipment used in this experiment is: CYB-YB-F1K type force sensor, SY-2 type acceleration sensor, RS-1616K(S) type pile foundation dynamic measuring instrument, excitation equipment for $4000 \mathrm{~kg}$ heavy hammer.

\section{STATIC LOADING AND DYNAMIC TESTING COMPARISON TEST SCHEME}

In order to better compare the bearing capacity of pile foundation static loading test and high strain test, the prestressed concrete pipe piles of the same specification will be used in this test. Test pile number is $1^{\#}$ in the test site I and test pile number is $2^{\#}$ in the test site II. The related parameters of test piles are shown in Table III.

\section{TABLE III. RELEVANT PARAMETERS OF TEST PILES}

\begin{tabular}{ccccc}
\hline $\begin{array}{c}\text { Test } \\
\text { site }\end{array}$ & $\begin{array}{c}\text { Number of } \\
\text { test pile }\end{array}$ & $\begin{array}{c}\text { Diameter of } \\
\text { pile / mm }\end{array}$ & $\begin{array}{c}\text { Buried length } \\
\text { of pile / } \mathrm{m}\end{array}$ & $\begin{array}{c}\text { Strength grade } \\
\text { of pile body }\end{array}$ \\
\hline I & $1^{\#}$ & 400 & 13 & C80 \\
II & $2^{\#}$ & 400 & 11 & C80 \\
\hline
\end{tabular}

In order to ensure the static and dynamic contrast test data, pile foundation reaches ultimate failure in static loading test, high strain dynamic testing of pile foundation will be executed at the same time. Before static loading test, displacement sensors will be arranged in the top of pile, fixed in the reference steel beam by magnetic core base. The test load will be loaded gradually by hydraulic jack, which mounted on the top of pile.

In order to measure the lateral resistance of pile in different soil layers, according to the distribution of soil in the test site (see table 1 and 2), strain meters will be arranged at the interface of different soil layers of pile body. In order to measure the resistance of pile end, pressure sensor will be fitted in the bottom of pile.

\section{TEST RESULTS AND ANALYSIS}

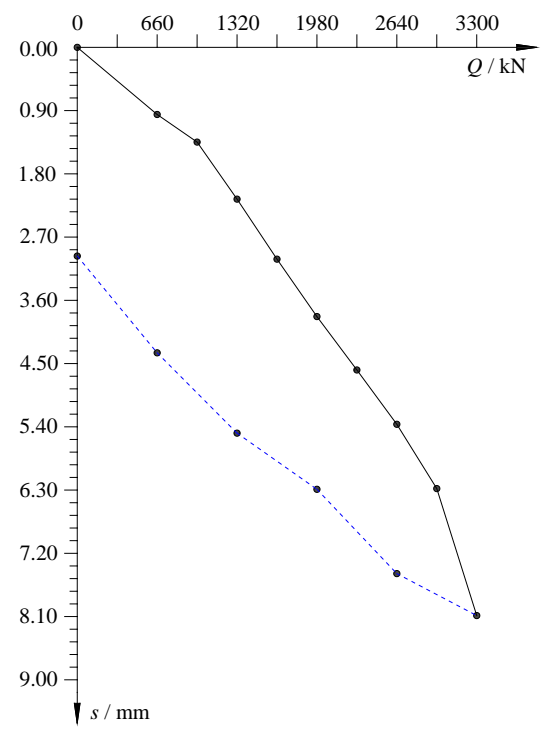

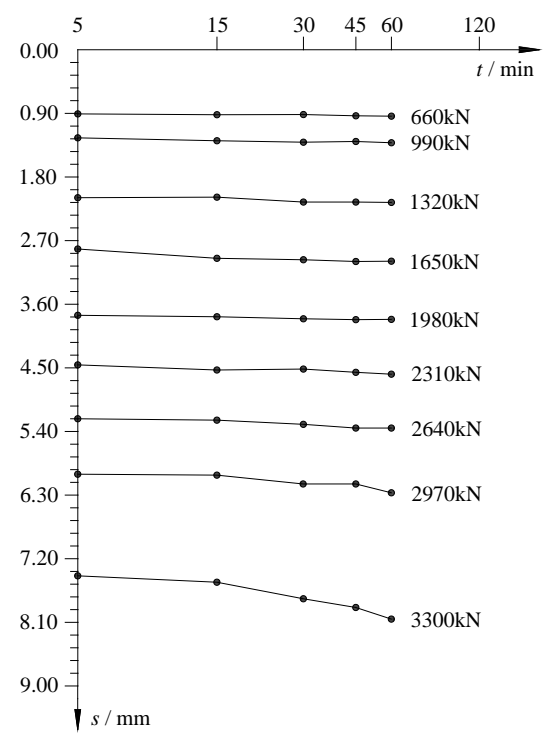

FIGURE III. Q-S AND S-LGT CURVES OF PILE 1\#

The Q-s curve and s-lgt curve of pile 1\# and 2\# in static loading test, are shown in Figure III and Figure IV.

From Figure III, pile $1^{\#}$ is loaded into $3300 \mathrm{kN}$, and the cumulative subsidence quantity of loading is $8.09 \mathrm{~mm}$. The cumulative rebound quantity of unloading is $5.12 \mathrm{~mm}$, and the rebound rate is $63.3 \%$. The Q-s curve is flat and no obvious fall section. The s-lgt curve is flat and arranged. Therefore, the vertical compressive ultimate bearing capacity of pile $1^{\#}\left(Q_{u}\right)$ is greater than or equal to $3300 \mathrm{kN}$.

From Figure IV, pile $2^{\#}$ is loaded into $3100 \mathrm{kN}$, and the cumulative subsidence quantity of loading is $5.05 \mathrm{~mm}$. The cumulative rebound quantity of unloading is $5.02 \mathrm{~mm}$, and the rebound rate is $71.2 \%$. The $Q-s$ curve is flat and no obvious fall section. The s-lgt curve is flat and arranged. Therefore, the vertical compressive ultimate bearing capacity of pile $2^{\#}\left(Q_{u}\right)$ is greater than or equal to $3100 \mathrm{kN}$.

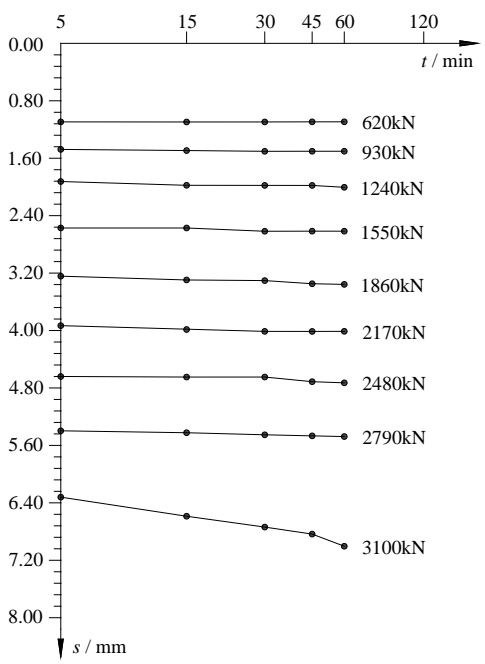




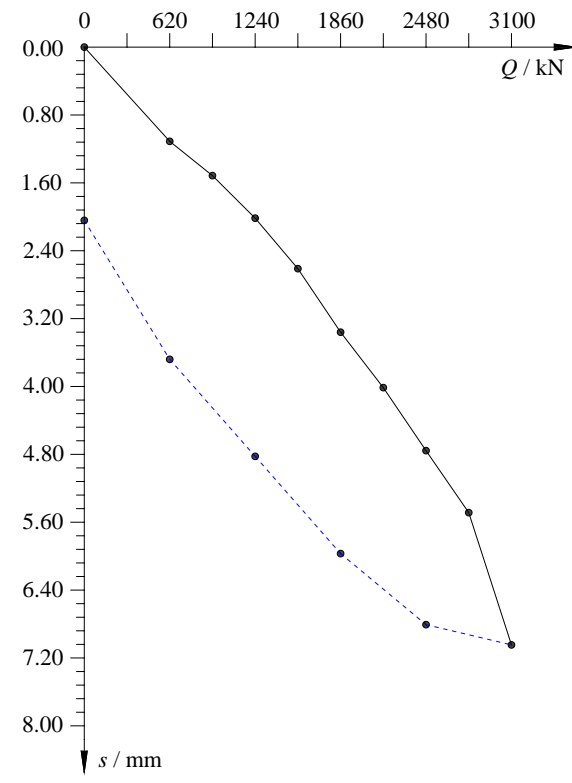

FIGURE IV. Q-S AND S-LGT CURVES OF PILE 2\#

The measured force wave and the measured velocity wave, the measured force wave and the fitting force wave of pile $1^{\#}$ and $2^{\#}$ in this high strain dynamic test, are shown in Fig.5-8.

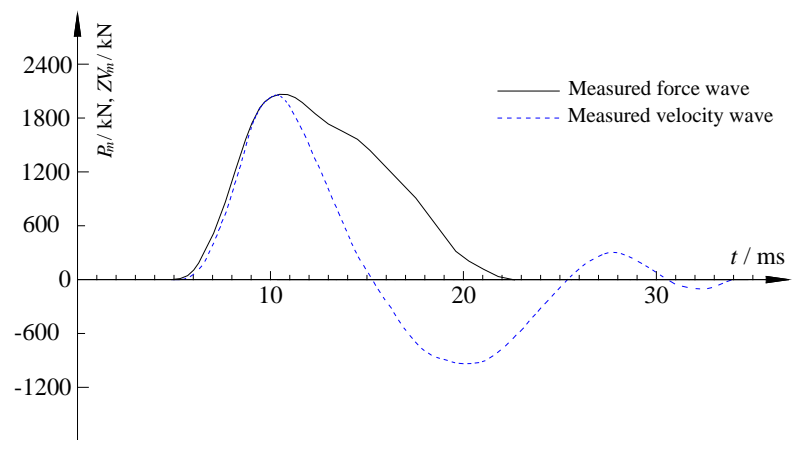

FIGURE V. MEASURED FORCE WAVE AND MEASURED VELOCITY WAVE OF PILE 1\#

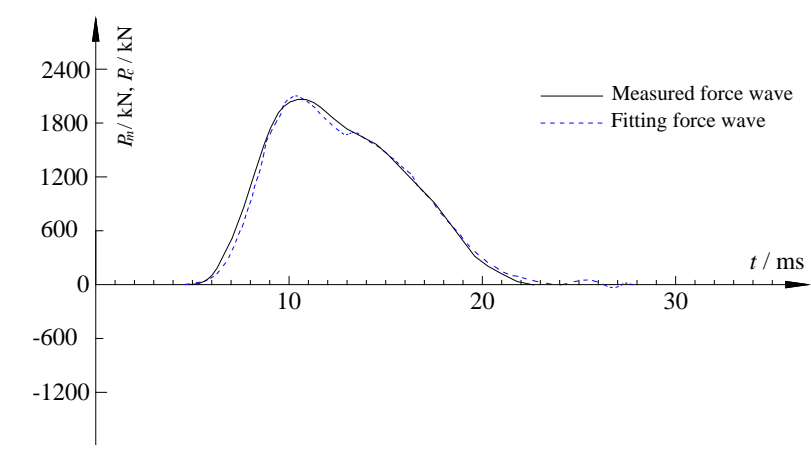

FIGURE VI. MEASURED FORCE WAVE AND FITTING FORCE WAVE OF PILE $1^{\#}$

From Figure V and VII, the rising section and the first peak of the measured force wave and the measured velocity wave of pile $1^{\#}$ and $2^{\#}$ are coincident, and it shows that there is no obvious effect of soil resistance at this time section.

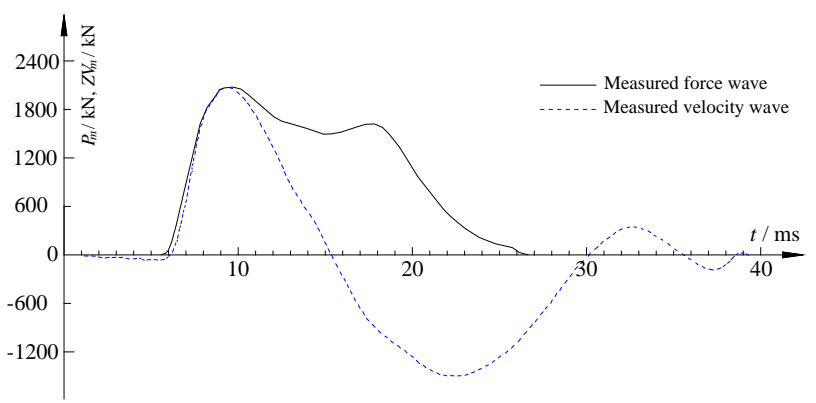

FIGURE VII. MEASURED FORCE WAVE AND MEASURED VELOCITY WAVE OF PILE 2\#

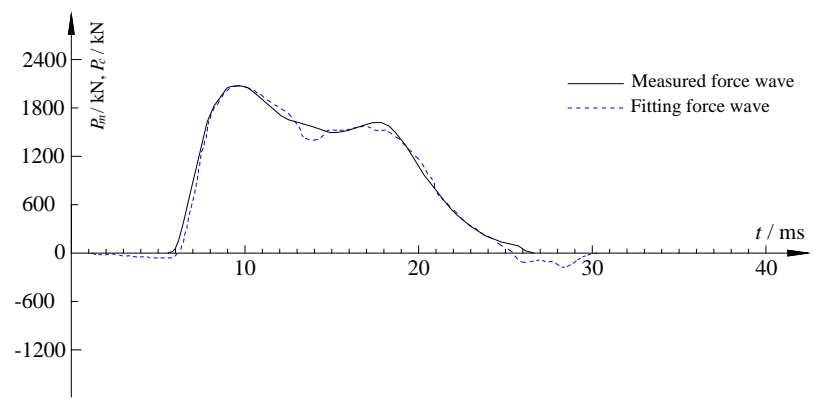

FIGURE VIII. MEASURED FORCE WAVE AND FITTING FORCE WAVE OF PILE 2\#

From Figure VI and VIII, the measured force wave and the fitting force wave of pile $1^{\#}$ and $2^{\#}$, based on the measured velocity wave as boundary condition, the calculated force wave will be fitted by adjusting the corresponding fitting parameter. Comparing the fitting force wave and the measured force wave of Figure VI and VIII, we can know that the two curves have basically the same trend.

Based on the pile-soil dynamic model, the corresponding calculating program is compiled by Matlab. According to soil parameters of test site, the measured cure can be fitted and analyzed by adjusting fitting parameter, and high strain testing results of the vertical compressive bearing capacity of test pile can be obtained, as shown in Table 4 .

\section{TABLE IV. HIGH STRAIN TEST RESULTS OF TEST PILES}

\begin{tabular}{cccc}
\hline $\begin{array}{c}\text { Number of } \\
\text { Test pile }\end{array}$ & $\begin{array}{c}\text { Total resistance } \\
\text { of pile side / kN }\end{array}$ & $\begin{array}{c}\text { Resistance of } \\
\text { pile end / kN }\end{array}$ & $\begin{array}{c}\text { Bearing capacity of } \\
\text { dynamic testing / kN }\end{array}$ \\
\hline $1^{\#}$ & 1282 & 1588 & 2870 \\
$2^{\#}$ & 943 & 1805 & 2748 \\
\hline
\end{tabular}

Comparing the results of static loading and dynamic testing in this test, we can obtain that the ultimate bearing capacity of static loading method of pile $1^{\#}$ and $2^{\#}$ is respectively $3300 \mathrm{kN}$ and $3100 \mathrm{kN}$, the ultimate bearing capacity of high strain testing method of pile $1^{\#}$ and $2^{\#}$ is $2870 \mathrm{kN}$ and $2748 \mathrm{kN}$, and the difference between static loading test and high strain testing is respectively $13.03 \%$ and $11.35 \%$. 


\section{CONCLUSION}

Based on the pile-soil dynamic model, the fitting calculating program is compiled by Matlab. The measured strain data were fitted and calculated, which and static load test results were compared and analyzed.

The static loading and dynamic testing results of pile vertical compressive ultimate bearing capacity of two test sites, and the difference of two test sites was respectively $13.03 \%$ and $11.35 \%$. Compared with the static loading method, the bearing capacity of pile foundation measured by high strain measured curve fitting method was lower.

According to the actual soil layer parameters of test site, by modifying the fitting parameters of pile-soil dynamic model, the calculated curve and the measured curve fitted well. The bearing capacity of pile foundation measured by high strain measured curve fitting method was relatively accurate.

\section{ACKNOWLEDGMENT}

This work was financially supported by the National Natural Science Foundation of China (51064009, 51464015), the Natural Science Foundation of Guangdong Province of China (2016A030313121), the Higher School Talent Introduction Project of Guangdong Province (A413.0210) and the Science and Technology Project of Huizhou City of Guangdong Province of China (2014B020004018).

\section{REFERENCES}

[1] Deqing Li, Chengyun Li, Li Chenghai. Diagnosis technology of pile foundation engineering quality [M]. China Building Industry Press, 2009.

[2] Juzhong Feng, Hang Wang, Jin Wei, et al. Model tests on vertical bearing performance of bridge pile foundation in loess gulch slope area [J]. Chinese Journal of Geotechnical Engineering, 2015, 37(12): 23082314. (in Chinese)

[3] Daijun Jiang, Chunxiang Guo. Long-term stability of bearing capacity of single pile in permafrost area on Qinghai-Tibetan Plateau [J]. Journal of Chang'an University (Natural Science Edition), 2016, 36(2): 59-65. (in Chinese)

[4] Duanduan Wang, Zhijun Zhou, Lü Yanda, et al. An experimental study of influence of drilling method on the bearing capacity of pile foundation in collapsible loess area [J]. Rock and Soil Mechanics, 2015, 36(10): 2927-2933. (in Chinese)

[5] Min Yang, Junwei Jin. Research progress on interaction of pile foundation with nearby existing subway tunnel [J]. Journal of Building Structures, 2016, 37(8): 90-100. (in Chinese)

[6] Dezhong Yu, Peifeng Cheng, Cheng Ji, et al. Static and dynamic contrast test for bearing capacity of refrozen bridge pile foundation in patchy permafrost regions [J]. Chinese Journal of Rock Mechanics and Engineering, 2015, 34 (Supp.1): 2845-2853. (in Chinese)

[7] Wuyu Zhang, Xuefeng Wang, Gan Yi, et al. The influence of off-center hitting on the signals in high strain dynamic test [J]. Industrial Construction, 2010, 40(8): 95-60. (in Chinese)

[8] Zhichen Yang. The research of the high strain dynamic testing parameters for foundation pile [D]. Jinan: Shandong Jianzhu University, 2013.

[9] Aijun Chen, Ming Wu, Huiman Chen. Structural test and detection [M]. Beijing: China Building Materials Industry Press, 2015.

[10] Anguo Chen, Dongjia Liu. Study on matching calculation for high strain test piles [J]. Chinese Journal of Engineering Geophysics, 2008, 5(2): 215-221. (in Chinese)
[11] Lei Xia. Study and application of signal matching method for high strain dynamic testing of pile [D]. Hefei: Hefei University of Technology, 2013. 